Table 1. Risk factors for low back pain according to occupational class

\begin{tabular}{|c|c|c|c|}
\hline Risk factors & $\begin{array}{c}\text { Healthcare workers } \\
\text { OR }(95 \% \mathrm{Cl})\end{array}$ & $\begin{array}{c}\text { Administrative workers } \\
\text { OR }(95 \% \mathrm{Cl})\end{array}$ & $\begin{array}{c}\text { Technical workers } \\
\text { OR }(95 \% \mathrm{Cl})\end{array}$ \\
\hline Age (years) & $1.00(0.98-1.03)$ & $1.10(1.04-1.16)^{\star * \star}$ & $1.04(1.01-1.09)$ \\
\hline Sex ratio & $1.15(0.71-1.84)$ & $1.99(0.55-7.24)$ & $0.84(0.28-2.54)$ \\
\hline Seniority in the firm & $1.42(0.76-2.64)$ & $0.95(0.24-3.83)$ & $5(1.4-17.83)^{\star \star}$ \\
\hline $\begin{array}{l}\text { Seniority in their current } \\
\text { position }\end{array}$ & $3.5(1.2-10.6)^{\star}$ & $1.04(0.35-3.12)$ & $11.3(1.1-112.1)^{\star}$ \\
\hline $\begin{array}{l}\text { Number of hours worked } \\
\text { per week }\end{array}$ & $0.76(0.26-2.21)$ & $10.07(1.02-99.69)^{\star}$ & - \\
\hline Office chair quality & $3.3(1.1-10.4)^{\star}$ & $5.97(1.16-30.63)^{\star}$ & $10(0.6-164.9)$ \\
\hline Heavy weight & $1.10(0.62-1.97)$ & $2.27(0.52-9.84)$ & $4.2(1.3-13.3)^{\star \star}$ \\
\hline Vibrations & $1.23(0.67-2.27)$ & $10.30(0.81-130.73)$ & $3.6(1.2-10.6)^{\star \star}$ \\
\hline Job satisfaction & $0.35(0.14-0.89)^{\star}$ & $0.74(0.10-5.58)$ & $0.66(0.17-2.53)$ \\
\hline
\end{tabular}

${ }^{*} \mathrm{p}<0.05 \cdot{ }^{* *} \mathrm{p}<0.01 \cdot{ }^{* * *} \mathrm{p}<0.001$

$\mathrm{p}=0.01$ ), and job satisfaction (OR 1.55, 95\% $\mathrm{Cl} 105-2.54, \mathrm{p}=0.048)$. The specific risk factors for each occupation are presented in Table 1.

Conclusions: In an institution like Douala General Hospital, where the administrative, technical and healthcare workers are subjected to the same professional stress in terms of quality of care and performance, we did not find any difference on prevalence among these 3 occupations.

Preventive measures must be performed for all staff but need to be tailored to each occupation.

Disclosure of Interest: None declared

DOI: 10.1136/annrheumdis-2017-eular.6750

\section{SAT0589 THERAPEUTIC EDUCATION IN THE MANAGEMENT OF FEARS AND BELIEFS IN PATIENTS WITH CHRONIC LOW BACK PAIN}

R. Maaoui ${ }^{1}$, A. Khezami ${ }^{1}$, I. Ksibi ${ }^{1}$, I. Lajnef ${ }^{1}$, H. Rahali ${ }^{1}$, R. Dhahri ${ }^{2}$, I. Gharsallah ${ }^{2}$, L. Metoui ${ }^{2}$, F. Lajili ${ }^{2}$, S. Othmani ${ }^{2} .{ }^{1}$ Physical and Rehabilitation Medicine; ${ }^{2}$ Internal Medicine, military hospital Tunis, tunis, Tunisia

Background: The notions of apprehension-avoidance and beliefs are among the psychosocial factors associated with the occurrence, maintenance and strengthening of the chronic painful process.

Therapeutic education is increasingly described in the literature as a means to manage these factors in order to limit the transition to a chronic stage.

Objectives: The aim of this study is to examine the effect of therapeutic education on fears and beliefs in chronic low back pain.

Methods: A prospective, comparative study was conducted with two groups of 50 patients each one having chronic low back pain. Both groups had benefited from the same physical rehabilitation program. The second group concurrently attended therapeutic education sessions.

Fears and beliefs of patients and their kinesiophobia were evaluated with the FABQ: Fear-Avoidance beliefs questionnaire and the TSK: Tampa scale of kinesiophobia for the evaluation of kinesiophobia index.

Results: The initial evaluation of apprehension-avoidance showed a high FABQ score in two groups. Management that was limited to physical rehabilitation demonstrated no effect on the apprehension-avoidance indices evaluated by the FABQ scale. However, there was a clear improvement in apprehension and avoidance in the $G 2$ and with a statically significant difference $(P=0.03)$.

An initial and high kinesiophobic score $(\geq 48)$ was noted in two groups. G1 patients showed no significant improvement in their TSK scores after the end of the program. G2 patients who benefited from a therapeutic education workshop improved their TSK scores significantly after the program completion compared to G2.

Conclusions: The integration of the patient into the therapeutic education workshops improved the behavior of apprehension and kinesiophobia. This further supports the usefulness of applying cognitive therapy to our patients when restructuring of preconceived ideas about movement and physical activities.

\section{References:}

[1] Nguyen C, Poiraudeau S, Revel M. Lombalgie chronique: facteurs de passage à la chronicité. Rev rhum.2009;76:537-42.

[2] Butron AK, Waddel G, Tilloston KM, Sumerton N. Information and advice to patients with back pain can have positive effects. A randomized controlled trial of a novel educational book in primary care. Spine. 1999;24:2481-91.

[3] Fritz JM, George SZ, Delitto A.The role of fear-avoidance beliefs in acute low back pain: relationships with current and future disability and work status.Pain. 2000;94:7-15

Disclosure of Interest: None declared

DOI: 10.1136/annrheumdis-2017-eular.4373

\section{SAT0590 FEARS AND BELIEFS IN PATIENTS WITH CHRONIC LOW} BACK PAIN AND SICK LEAVE: WHAT RELATIONSHIP?

R. Maaoui ${ }^{1,1}$, A. Khezami ${ }^{1}$, I. Ksibi ${ }^{1}$, I. Lajnef ${ }^{1}$, H. Rahali ${ }^{1}$, R. Dhahri ${ }^{2}$ I. Gharsallah ${ }^{2}$, L. Metoui ${ }^{2}$, B. Louzir ${ }^{2}$, F. Lajili ${ }^{2}$, S. Othmani ${ }^{2} .{ }^{1}$ Physical and Rehabilitation Medicine, ${ }^{2}$ Internal Medicine, military hospital Tunis, tunis, Tunisia

Background: The occupational impact of low back pain is generally assessed in terms of absenteeism and duration of sick leave. A non-return to work greater than eight days has been considered a poor prognosis factor. Several psychosocial factors have been identified as the original cause.
Objectives: Studying the impact of erroneous beliefs, avoidance behaviors, apprehension and fear of movement on sick leave in patients with chronic low back pain.

Methods: A prospective study was conducted in patients with chronic low back pain patients. The notion of apprehension-avoidance was evaluated by the Fear Avoidance Beliefs questionnaire (FABQ), fear of movement by the Tampa scale of kinesiophobia (TSK) and functional disability by the Functional Disability Scale Of low back pain: EIFFEL (French version of Roland Disability Questionnaire). A study of the correlations between these different parameters and the duration of sick leave was carried out subsequently.

Results: Our study included 100 patients. The findings revealed a 95\% absenteeism rate including $67 \%$ with a sick leave of more than one month. The FABQ, TSK and EIFFEIL scores were high.

The statistical study concluded that there was a positive and significant correlation between sick leave time, fears and erroneous beliefs ( $r=0.147, P=0.033)$. We also found a positive and significant correlation between the duration of sick leave and kinesiophobia. There were no statistically significant correlations between sick leave and functional disability.

Conclusions: The high scores of FABQ and TSK confirm the important role of false beliefs and fear of movement in the genesis of chronicity in chronic low back pain as reported in the literature. The positive correlations found in our study reinforce the theory of the deconditioning of these patients following their beliefs. Management of these factors would be an important contribution to limit sick leave times in chronic low back pain.

References:

[1] Williams RA, Pruitt SD, Doctor JN, Epping-Jordan JE, Wahlgren DR, Grant I et al.The contribution of job satisfaction to the transition from acute to chronic low back pain. Arch Phys Med Rehab.1998;79:366-74.

[2] Ratinaud MC,Chamoux A,Glace B,Coudeyre E. Job satisfaction evaluation in low back pain: a literature review and tools appraisal. Ann Phys Rehabil Med. 2013;56(6):465-81.

[3] Fayad F, Lefevre-Colau MM, Poiraudeau S,Fermanian J, Rannou F, Wlodyka Demaille $S$ et al. Chronicité, récidive et reprise du travail dans la lombalgie: facteurs communs de pronostic. Ann Readap Med Phy.2004; 47:179-88.

[4] Gronblad M, Jarvinen E, Airaksinen O, Ruuskanen M, Hamalainen H, Kouri JP. Relationship of subjective disability with pain intensity, pain duration, pain location and work -related factors in non operated patients with chronic low back pain. Clin J Pain. 1996;12:194-200.

Disclosure of Interest: None declared

DOI: 10.1136/annrheumdis-2017-eular.4385

\section{SAT0591 LOCAL STEROID INJECTION VERSUS WRIST SPLINTING FOR CARPAL TUNNEL SYNDROME: A RANDOMIZED CLINICAL TRIAL}

$\underline{\text { H. So }}^{1}$, V. Chung ${ }^{2}$, J. Cheng ${ }^{3}$, M.L. Yip ${ }^{4} .{ }^{1}$ Medicine and Geriatric, Kwong Wah Hospital, Kowloon; ${ }^{2}$ Faculty of Medicine, The Chinese University of Hong Kong,

New Territories; ${ }^{3}$ Department of Occupational Therapy, Kwong Wah Hospital;

${ }^{4}$ Integrated Diagnostic and Medical Centre, Tung Wah Groups of Hospitals, Kowloon, Hong Kong

Background: Carpal tunnel syndrome (CTS) can lead to significant symptoms and loss of hand function. It also has a great socio-economic impact. However, there is no consensus regarding its best treatment up to this moment. Local steroid injection and wrist splinting are among the most popular nonsurgical treatment options. Previous studies have confirmed their respective effectiveness. However, there is no high quality head to head comparative study regarding the two treatments in the literature.

Objectives: To compare the efficacy of local steroid injection and nocturnal wrist spiniting for CTS.

Methods: We conducted a prospective randomised parallel clinical trial comparing the efficacy of local steroid injection and nocturnal wrist splinting in patients with CTS. The well validated and disease specific Boston Carpal Tunnel Questionnaire (BCTQ) was employed and its score at 4 weeks after treatment was used as the primary outcome measure. Important secondary outcomes included the patient satisfaction, the change of an objective finger dexterity test 9-hole-peg test, and the side effects.

Results: Twenty-five patients in the local steroid group and 25 patients in the wrist splinting group completed the study procedures. The baseline patient and clinical characteristics of the two treatment groups were similar. At 4 weeks after treatment, there was significant improvement of the BTCQ scores in both the steroid group and splinting group. There was improvement of the 9-hole-peg test only in the steroid group but not in the splinting group. However, there was no statistically significant difference in the changes of BTCQ scores between the two groups after treatment. Patient satisfaction score was higher in the steroid group. Patient in the steroid group took less painkillers after treatment. Four patients developed side effects after splinting and 3 after local steroid injection, which was not statistically significant.

Conclusions: Although local steroid injection and nocturnal wrist splinting were equally effective in the treatment of patients with CTS, only the former improved objective hand function. Local steroid injection also resulted in better patient satisfaction and less painkiller use without causing more side effects.

Disclosure of Interest: None declared 